\title{
Publisher's Note: Impact of trailing edge shape on the wake and propulsive performance of pitching panels [Phys. Rev. Fluids 2, 014702 (2017)]
}

T. Van Buren, D. Floryan, D. Brunner, U. Senturk, and A. J. Smits

(Received 22 May 2017; published 26 May 2017)

DOI: 10.1103/PhysRevFluids.2.059901

This paper was published online on 9 January 2017 with a typographical error on page 3 . The second line in the Results section on page 3 should read as "of the spanwise vorticity, using thresholds of $\omega_{z}^{*}= \pm 1.0$ where $\omega_{z}^{*}=\omega_{z} c / U_{\infty}$. The wake..." The paper has been corrected as of 23 May 2017. 